\title{
Simulation of Thermal Stratification in Urban Man-made Lakes
}

\author{
${ }^{1}$ J. Nouri, ${ }^{2}$ H. Rahimipour and ${ }^{3}$ R. Nezakati \\ ${ }^{1}$ Department of Environmental Health Engineering, School of Public Health, \\ Center for Environmental Research, University of Tehran Medical Sciences, Tehran, Iran \\ ${ }^{2}$ Soil Conservation and Watershed Management Research Center, Tehran, Iran \\ ${ }^{3}$ Department of Environmental Engineering, \\ College of Engineering, North Tehran Branch, Islamic Azad University, Tehran, Iran
}

\begin{abstract}
Chitgar artificial lake, located in the urban District-22 Municipality of Tehran northwest of Tehran, Iran is by volume 10 Million Cubic Meter (MCM), by depth average 10 meters (m.) and by area 225 hectares (ha) as the Iran's largest man-made lake. The most important water resources of the district, which can support the lake water, are Kan River, municipal runoff, the middle part watersheds runoff and the treated wastewater of urban regions. In this study the way to take water from each resource individually or some of them together have been discussed and twelve different choices of resources maintain the lake water have been introduced. Thermal stratification is one of the most important parameters that can affect the lake water quality after construction in regard to Tehran climatic conditions. In this research Water Quality for River and Reservoir Systems (WQRRS) model has been run to every 12 aforementioned choices individually to predict the probable thermal stratification in the lake for each one. This simulation has been done during a five-year period, which is assumed to be a typical period of time in this study. The needed input data to run the model are quality factors, meteorological data, and geometrical characteristics of the reservoir, the characteristics of inflow and also the needed coefficients for the model. These data have been collected from hydrometric and meteorological stations of the region and also the results of other researchers. After running the model the simulation results show that the Kan River, as one of the proposed water resources, has the least difficulties in thermal stratification.
\end{abstract}

Key words: Man-made Lake, Water Resources, Water Quality, Thermal Stratification

\section{INTRODUCTION}

The predicted lake, called Chitgar Lake is located in the District-22 Municipality in the north-west of Tehran, Iran. The area is about 224 hectares with a volume of $10 \mathrm{MCM}$ and a maximum elevation of 16 meters $^{[1]}$. It is located between elevations of 1248 to 1268 meters above sea level and on the eastern side of Chitgar urban- planted forest. As the lake is situated in the urban region, there are limits of 150 meters all around $\mathrm{it}^{[2]}$. Predicted characteristics of the lake reservoir have been illustrated in Table 1. Thermal stratification is one of the most important photochemical phenomena, which are because of existence the lakes. The sunshine heats the surface of the lake and makes a warm layer of water with a low density. Then a layer with higher density and lower temperature will stay under this condition ${ }^{[3,4]}$. In this way the lake is stratified to epilimnion, metalimnion and hypomnion layers ${ }^{[5]}$.

These three layers are not completely separated from each other, water fluctuations; different hydrological and meteorological factors affect each layer ${ }^{[6]}$.

Thermocline is a very significant layer, which is formed between epilimnion and hypolimnion ${ }^{[7]}$.
In this layer, which is generally formed in the summer, the temperature decreases more than one degree by every meter increase in depth ${ }^{[8]}$.

Thermocline prevents the vertical mixing of upper and lower layers, so the concentration of dissolved oxygen will not be homogeneous among different layers $^{[9]}$. In this way the concentration of oxygen in upper layer (epilimnion will be higher than the lower one (hypolimnion) which leads to decline of the lake water quality specially in deep areas ${ }^{[10]}$. In this study the probability of thermal stratification in Chitgar man made lake has been assessed. If the lake water is supported by various resources this probability will differ this has been simulated by using WQRRS model.

\section{MATERIALS AND METHODS}

In this research the water resources in the region, suitable for taking water to maintain the lake, have been assessed by quality and quantity. The next step is using simulation to predict the difficulties, which may threaten the water quality of lakes.

One of these difficulties is thermal stratification. Here using Water Quality has simulated the probability of thermal stratification for river and reservoir systems model. 
In this procedure the simulation has been done for every twelve proposed choices to support the lake water, separately. Eventually the results have been compared and discussed.

One of the most important parameters in the construction of artificial lakes is to provide water to make the reservoir full. So in this study, the water resources of District-22 of Tehran Municipality have been assessed and introduced as follows: (1) Kan River, (2) Vardavard River, (3) Municipal runoff (4) The middle part watersheds runoff, (5) Treated urban wastewater, (6) Ground water resources.

According to studies, Varavard River is not suitable to be used for giving water to the lake because of its technical and installation problems. Ground water resources don't have enough water to support the lake. So among the six mentioned resources, only the four other resources have been assessed. As long-term statistical data are needed to plan these water resources to support the lake, so a period of 43-year statistic (1955-1998) from hydrometric stations in the region have been used. By assessing the average long-term statistics of precipitation, it has been concluded that there are 26 dry years and 17 wet years. In this way $60 \%$ of the years are dry and $40 \%$ is wet. So there is a need to find a similar period of time in order to do the act simulation in the same condition.

Assessment of long-term statistics shows that there is a five- year period (the typical period) which its first two years $(40 \%)$ are related to wet years (1972-73 to 1973- 74) and its last three years $(60 \%)$ are related to dry years (1976-77 to 1977-75). The simulation of taking water from existing water resources is based on this typical period of time. In this planning the maximum volume of the lake reservoir will become full during wet years.

In this part of the study, the results of assessing four water resources to support the lake are given:

* Kan River is one of the main rivers in Tehran plain, which has the average annual inflow of about 80 MCM. The quality of its water suitable to maintain the lake. As the river has its maximum flow in spring, it is possible to get water in this season. This river would be able to support the lake with a volume of about 31 million cubic meters annually.

* Municipal runoffs; based on the results of hydraulic and hydrologic studies, topographical data, slope and exit maps of the region, the network of collecting runoff in the whole region are divided into 16 areas. Researches show that among these 16 areas, it is just possible to take water from five areas in order to support the lake water. The volume of annual runoff of these five areas is about 2.13 MCM. Municipal runoff can be so polluted as municipal wastewater and this is because of the passing through of water from urban areas, which can enter different pollutants with it. So it is necessary to assess the quality of the runoff before entering the lake ${ }^{[11]}$.

* The middle part watersheds runoff; the total area of the middle part watersheds is less than 35 square Kilometers $\left(\mathrm{Km}^{2}\right)$ and it includes two sub areas. The average annual inflow of these sub areas is totally 5.37 million cubic meters. Physiological assessments show that low inflow in these sub areas, the sharp slope of streams, the relatively high expense of exploiting and unsuitable topographical conditions to transfer water to the lake, makes taking water from all sub areas completely, impossible. The planning has therefore been done in $10 \mathrm{sub}$ areas by the total inflow of about 1.5 MCM annually (1).

* The treated wastewater of urban region; at present there are some scattered residential areas in District-22 of Tehran without any installations and systems to collect and treat urban wastewater. Thus it has been predicted to construct a treatment plant in the southern part of Chitgar planted forest. If the treated urban wastewater and its stable quality were available, it would be possible to use this resource in order to maintain the lake. The annual average volume of the treated urban wastewater is 22.6 million cubic meters (2).

In this study each of these four resources has been assessed individually or as a coalescence of some of them.

Here in Table 2 twelve various choices have been suggested to support the lake water.

In the next step of studies, the water quality of river reservoir systems model has been utilized to simulate the probability of thermal stratification in the lake.

In this procedure each of twelve choices has been assumed to be the resource of maintaining the lake water individually and then thermal stratification has been simulated for the assumed resource.

WQRRS model has been developed by the U.S. Army Corps of Engineers ${ }^{[12]}$. This is a comprehensive ecological simulation model for reservoirs and estuaries, which are designed as a one-dimensional model. The aforementioned model consists of three separate but integrated modules; the reservoir module, the stream hydraulic module and the stream quality module (WQRRS manual) in this research the reservoir Water Quality for River-Reservoir Systems-Reservoir model have been utilized. It is possible to simulate physical, chemical and biological factors by using this Module. In this part of the study, the input data requirements for the reservoir module have been collected.

These requirements can be divided into the following categories:

* Title: Chitgar Lake 
* Water quality specifications that are needed at this stage of simulation and other general data such as date and time of the first and the last simulation (day, month, year), the intervals of simulation (in terms of hourly).

* Physical data such as meteorological data, general reservoir geometry data (volume, area, elevation), dispersion coefficients, inflow and withdrawal location data.

* Physical, chemical and biological coefficients that are the own model coefficients have been used here.

* Initial quality conditions; in this study the factors which are measured in the main proposed water resources to support the have been used.

* The specifications of inflows during a simulation period, here the monthly average inflow is considered during a typical period of simulation (a 5-year period).

* Meteorological data based on date and time; the whole data have been received from Mehrabad Synoptic Meteorological station with 3-year intervals during the typical period of simulation.

* Daily withdrawal rates during the typical period of simulation.

\section{RESULTS AND DISCUSSION}

Input data requirements for the model having been collected from existing data and statistics, have been utilized and the model has been run. The thermal stratification simulation in the lake during the typical period of simulation (the water years of (1972-73 to 1976-77) has come to an end. Figure 2 to 13 show the variations of temperature as compared with depth in the lake reservoir during the mentioned period. It should be noted that the numbers given on the Figures show temperature in centigrade degree.

Figure 2 shows that the variations of temperature as compared with depth are linear. So it should be said that if the lake water has been supported by using this resource (choice1), thermal stratification would happen weakly just in some warm months of the year.

Figure 3 shows that the variations of temperature as compared with depth are linear in all month of the year. So if the lake water has been supported by using this resource (choice 2), the probability of thermal stratification will be too weak.

Figure 4 shows that the variations of temperature as compared with depth (thermal stratification) are relatively rough only at the beginning of simulation in deep parts of the reservoir in the summer. This stratification will disappear at the end of modeling. There is no thermal stratification during the remained months.
In Fig. 5 thermal profiles have very minute variations during the period of modeling. It can be predicted that there will be a very weak thermal stratification in the lake, if choice 4 can support its water.

Figure 6 shows that the variations of temperature with relation to depth are very high in summer but when it is full, the lake water will overturn and thermal stratification will disappear. Although the thermal stratification will disappear when the weather becomes colder, the probability of the stratification through choice (5) is more than other choices. The reason is that the temperature profiles are very near together in Fig. 6. In Fig. 7 as it is shown in the model, the variations of temperature profiles in depth are linear. There are some small variations about 2 to 3 centigrade degrees in the depths of more than 5 meters, which is not dangerous in creation of thermal stratification.

In the model is given in Fig. 8 the variation of temperature with relation to depth are linear and the probability of thermal stratification is very weak.

Figure 9 shows that at the beginning of the typical period of simulation, the variations of temperature comparing with depth is linear. At the end of the spring and at the beginning of the summer of the first year of modeling, a very small slope has been seen in temperature profile at the bottom of the reservoir. This variation in temperature in relation to depth is less than one-centigrade degree per depth meter, so the probability of thermal stratification is very weak in this choice.

Figure 10 shows that there are very minute variations of temperature with relation to depth during the majority of the typical period of simulation months. There has been a minute thermal stratification just in the summer of the first modeling year and this phenomenon becomes very weak during next years.

The model given in Fig. 11 shows that the temperature profiles with relation to depth have small variations during the majority of the typical period of simulation months, however the probability of thermal stratification in summer in depths of less than 3 meters still exists. When the season changes this stratification will disappear because of fall overturn.

The model given in Fig. 12 shows that temperature variation in relation to depth is linear but in some parts especially near the bottom of the reservoir, there are some slopes in summer and the late spring. These slopes are very low especially at the beginning of the modeling typical period and will disappear when the season changes and it becomes colder.

Figure 13 shows that there is thermal stratification in summer and in late spring in depths of less than 3 meters. This stratification will disappear when the season changes and fall overturn happens. This phenomenon has been repeated during the whole typical period of simulation. 


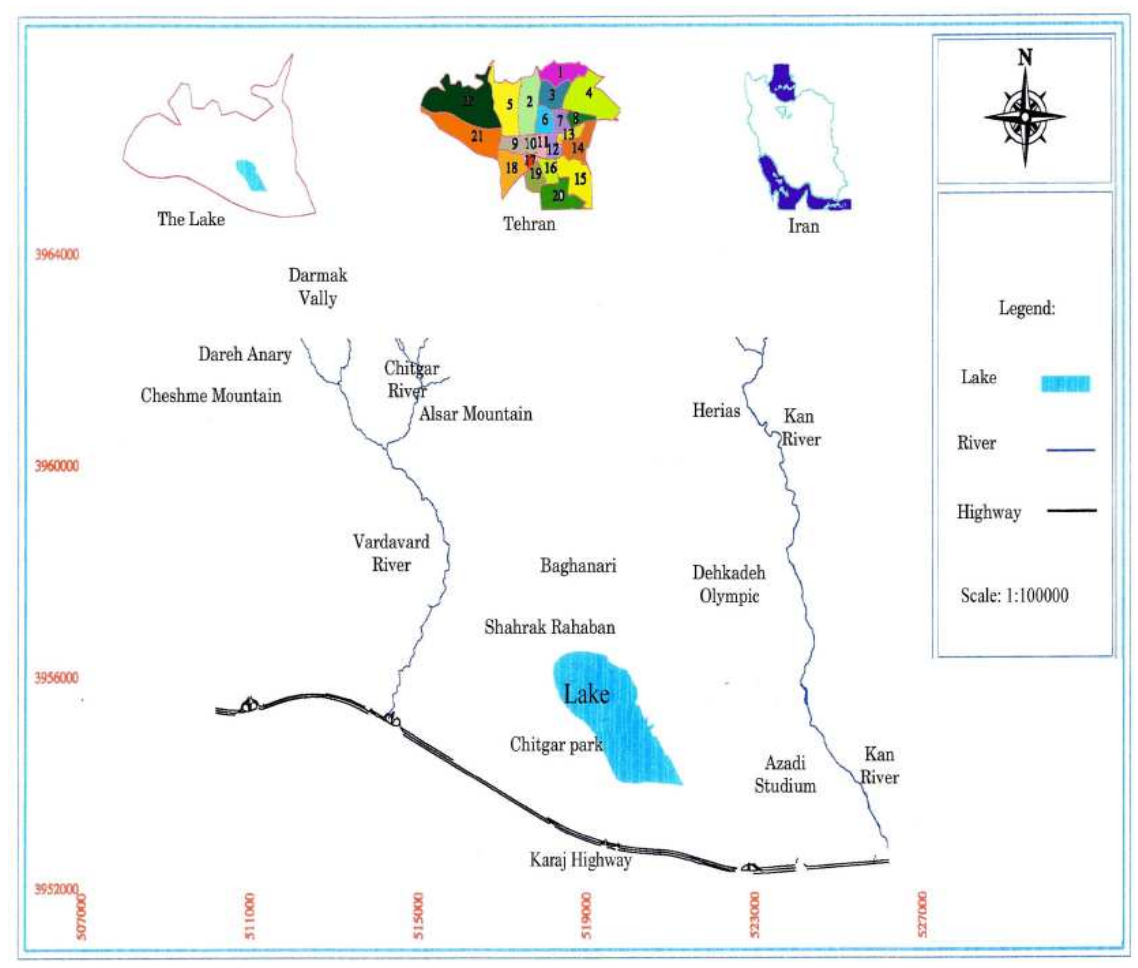

Fig. 1: Map of the man-made lake in district 22 municipalities of Tehran

Depth

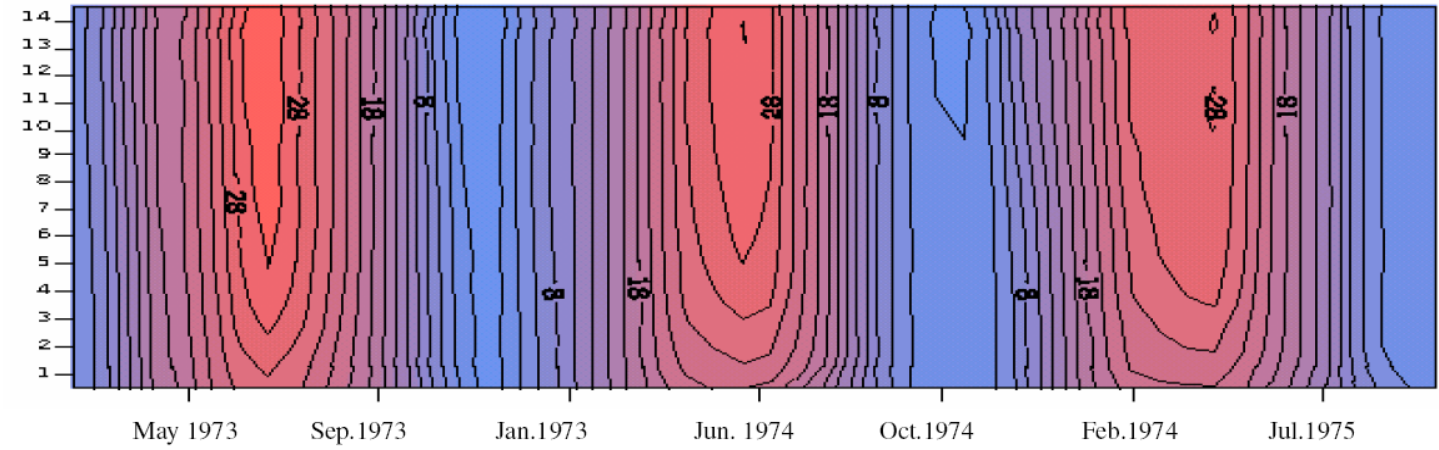

Fig. 2: Simulation and Prediction of Temperature Variations as Compared With Depth and Time (Thermal Stratification) for Treated Urban Wastewater (Choice 1) During the Typical Period of Simulation (1972-1977)

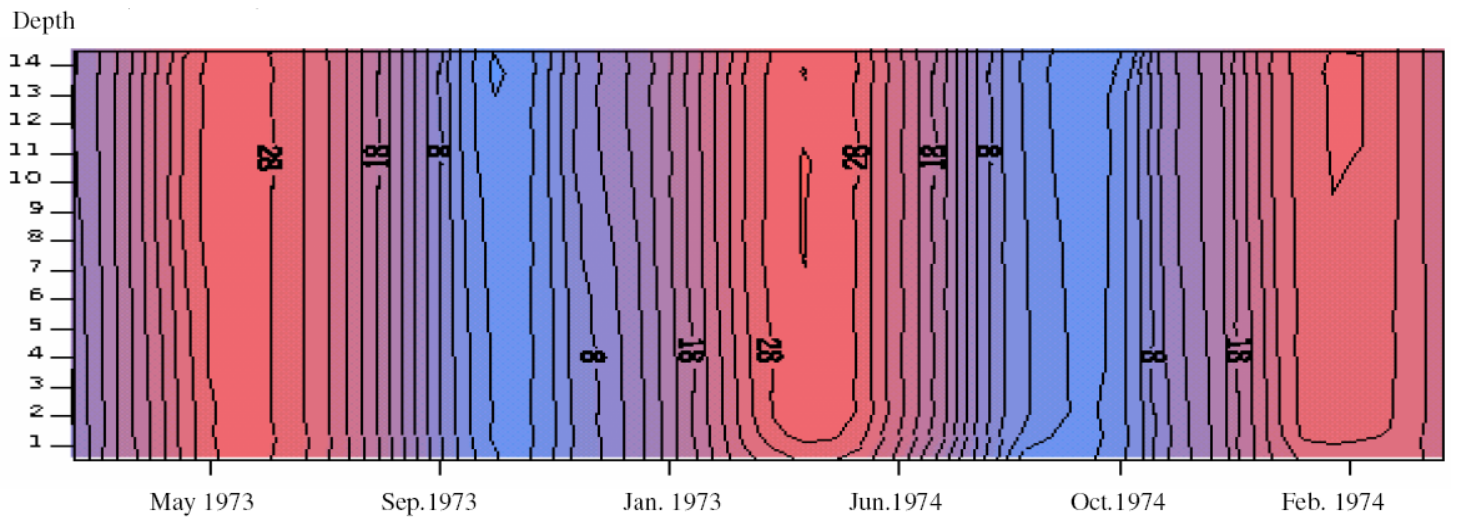

Fig. 3: Simulation and Prediction of Temperature Variations as Compared With Depth and Time (Thermal Stratification) for Kan River (Choice 2) During the Typical Period of Simulation (1972-1977) 


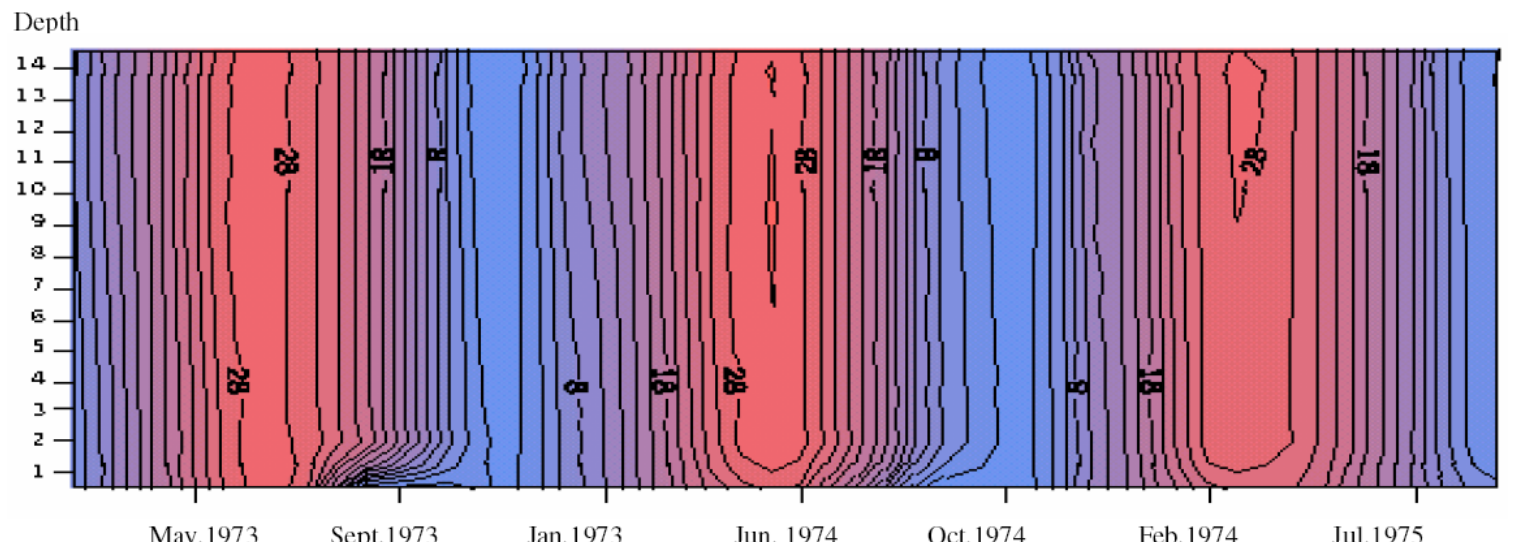

Fig. 4: Simulation and Prediction of Temperature Variations as Compared With Depth and Time (Thermal Stratification) for Kan River and Municipal Runoff Together (Choice3) During the Typical Period of Simulation (1972-1977)

$$
\text { Depth }
$$

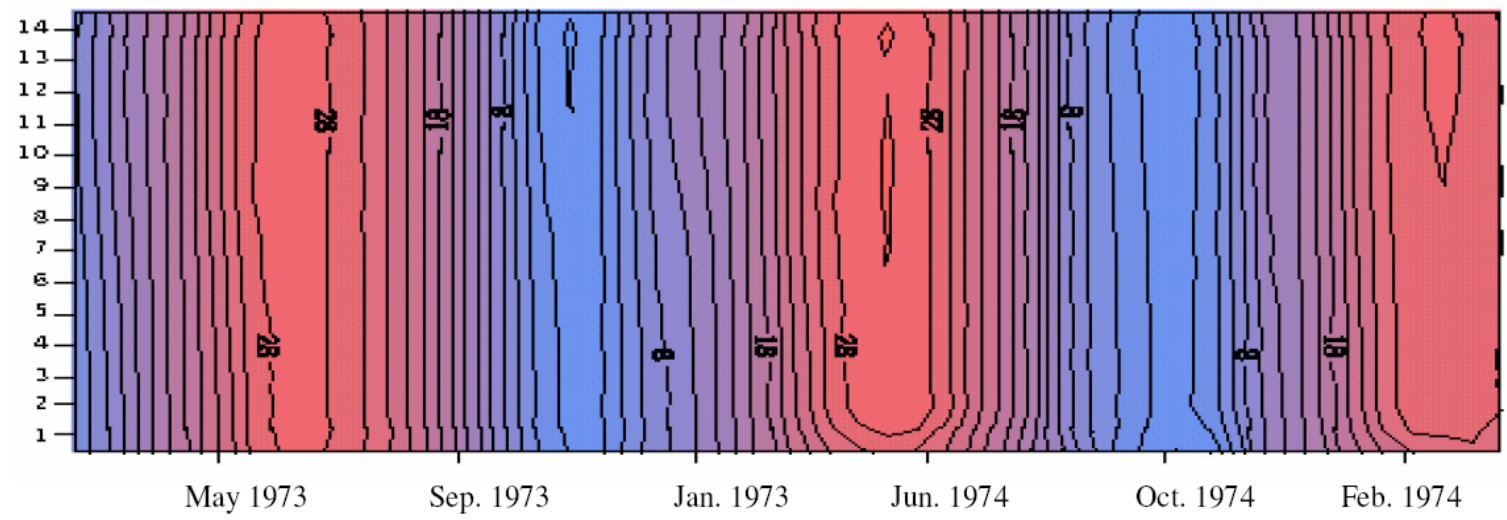

Fig. 5: Simulation and Prediction of Temperature Variations as Compared With Depth and Time for Kan River and the Middle Part Watersheds Runoff Together (Choice4) During the Typical Period of Simulation (19721977)

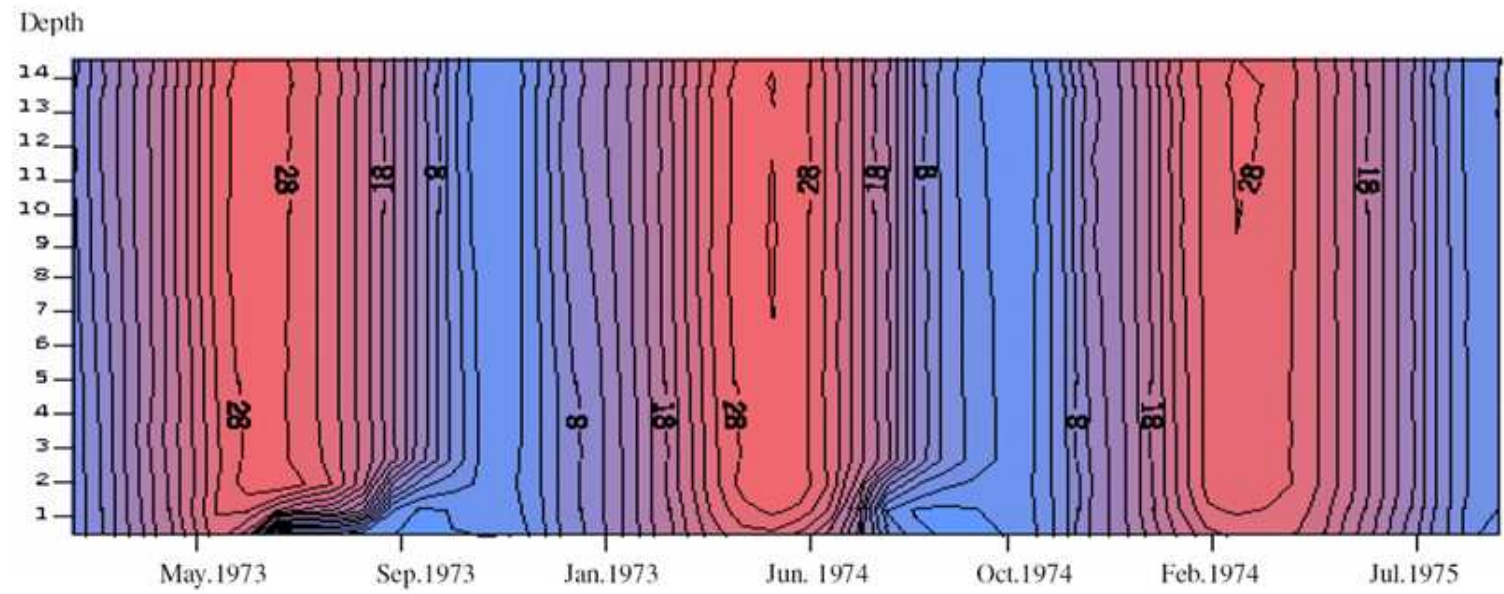

Fig. 6: Simulation and Prediction of Temperature Variations as Compared With Depth and Time (Thermal Stratification) for Kan River, Municipal Runoff and the Middle Part Watershed Runoff Together (Choice 5) During the Typical Period of Simulation (1972-1977) 


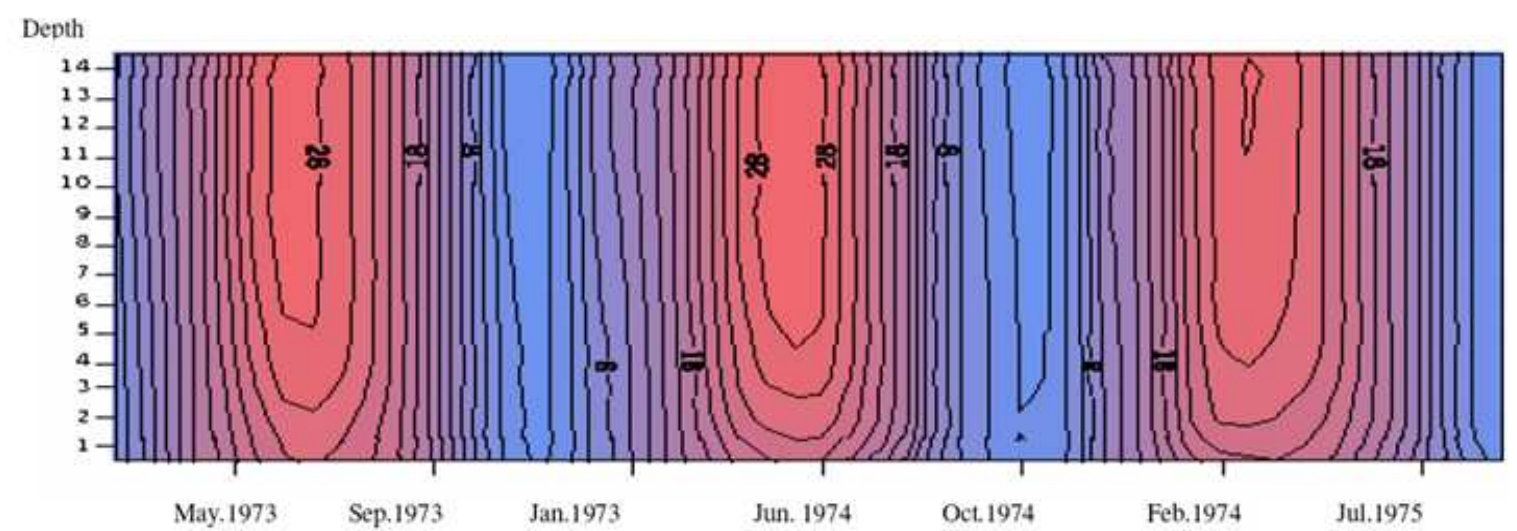

Fig. 7: Simulation and Prediction of Temperature Variations as Compared With Depth (Thermal Stratification) and Time for Municipal Runoff and the Treated Urban Wastewater Together (Choice 6) During the Typical Period of Simulation (1972-1977)

Table 1: Proposed Characteristics of Chitgar Lake Reservoir (2)

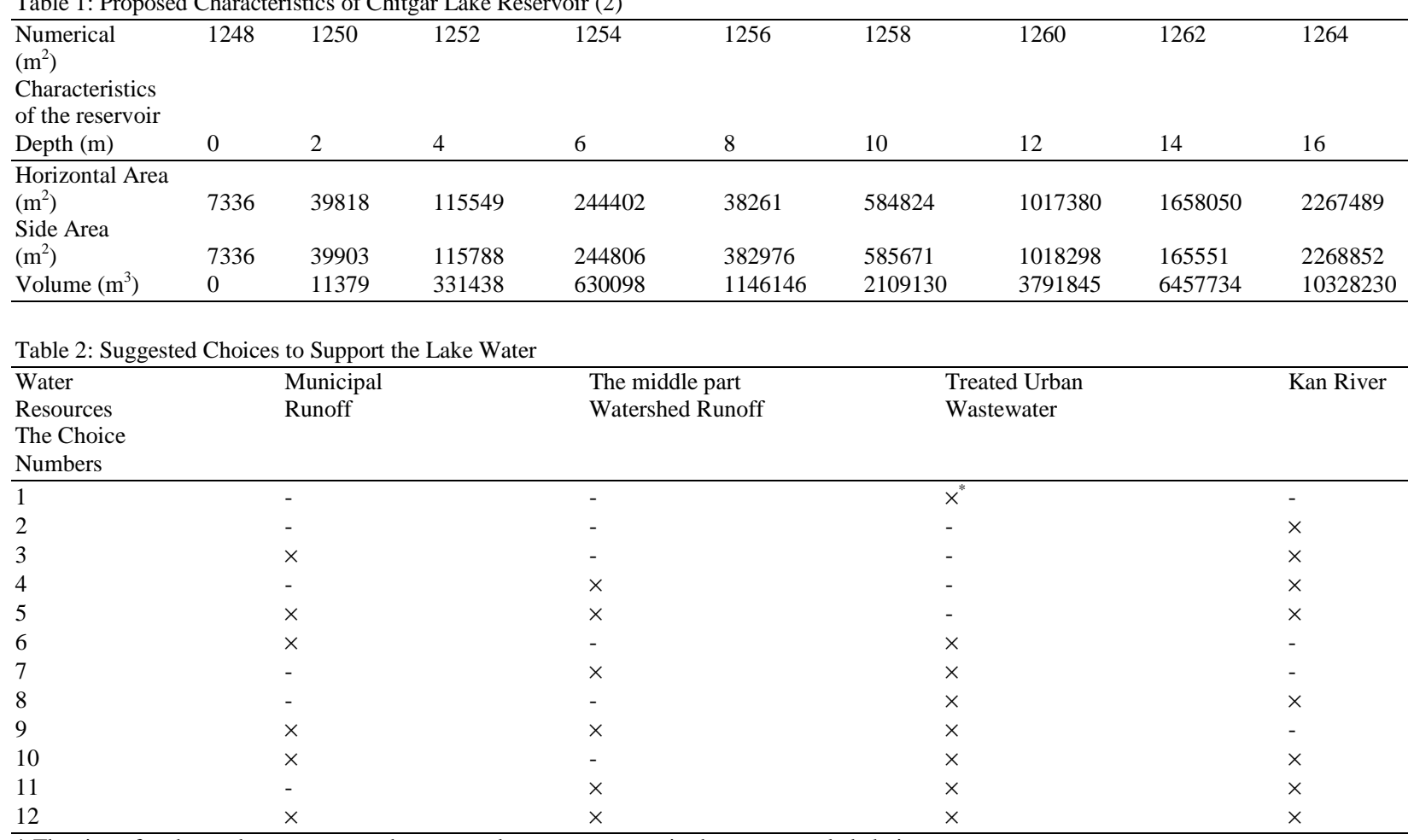

* The sign of $x$ shows those resources that are used to support water in the corresponded choice

\section{CONCLUSION}

The creation of thermal stratification in the warmer months of the year is a natural trend in lake reservoir. This will disappear when the weather becomes cold and the water of the lake overturns; therefore taking water from resources, which may have thermal stratification, should be done when the water quality is very little and the need is too much.

In this study there are some water resources, which have suitable quality and quantity; therefore it is not necessary to utilize the ones that a short- term thermal stratification of them has been predicted. Water temperature increase affects various factors such as dissolved oxygen, life of aquatic species and water quality. The formation of thermal stratification leads to decrease of dissolved oxygen in water especially at the bottom of the reservoir. If this stratification stabilizes for a long time, it will threaten the lake water quality more.

Thermal stratification stabilization in lakes leads to acceleration of a biotic activity at the bottom of the reservoir, so the taste, odor and appearance of the water will become unacceptable. Therefore the usage of water resources, which have short-time and unstabilized thermal stratification, may have deep effects on the lake 
water quality in a long time. The results of various thermal stratification choices of modeling comparing to each other are as follows: Choices (1), (2), (4), (6) and (7) have the least difficulties of thermal stratification Among these choices, choice (2) related to Kan River, is being recommended more than others. In choices (3), (8) and (9) thermal stratification happens at the beginning of the modeling typical period, but at the end of this period, stratification will disappear. Taking water out of these resources would only be recommended when the necessity and obligation is felt. In choices (5), (10) and (12) thermal stratification are more servers comparing with other choices and taking water out of these resources wouldn't be recommended.

As thermal stratification at the bottom of the lake reservoir is more likely to happen, therefore it is possible to take water from deep parts of the lake especially in warm seasons in order to irrigate green environment around the lake and the green plants of Chitgar park next to it. In this way water circulation will be done properly. The suitable management of the basin to prevent polluted inflows to the lake and treatment of waste-water, which may flow into it, will reduce the probability of thermal stratification. Moreover agricultural and urban wastewater flow should be controlled seriously as it contains too much nitrogen and phosphorous. If the amount of these micronutrients in water increases, the density difference between the epilimnion and hypolimnion will increase too. In this way epilimmion absorbs too much sunlight and so the temperature difference between layers will increase, therefore an extreme thermal stratification will happen.

\section{REFERENCES}

1. Anonymous, 2002. The report of assessment of installation to take water and passing it through Chitgar Lake, assessing water choices and giving the best one. Water and Watershed Management Research Jahad Coopreation Publication.
2. Anonymous, 2002. The report of ecosystem assessment and water quality. Water and Watershed Management Research Jahad Cooperation Publication.

3. Choi, J. and J. Koo, 1993. Monthly impact of nonpoint sources to Hoedony Lake, Korea. Water Sci. Technol., 28: 137-142.

4. Horne, A.J. and C. R. Goldman 1994. Limnology. McGraw Hill Internationals Publication, 2nd Ed.

5. Atsushi, I. and O. Toshiyuki, 1998. Estimation of urban non-point source pollution in the Lake Biwa basin. Water Sci. Technol., 38:157-163.

6. Holland, S.W. and Yoon, 1997. Lake water quality management based on seasonal thermal stratification in Lake Mowa. VA, Aesthetics in the Constructed Environment Proceedings of the Annual Water Resources Planning and Management Conference, ASCE, New York, pp: 610-615.

7. Halley, M.C., 1993. Lake Water Quality Management. Proceeding of the Symposium on Engineering Hydrology, San Francisco, CA, V.S.A. publ., 557-562.

8. Copeland, C., 1996. Great Lakes Water Quality: Current Issues. CRS Reports to Congress, Redistributed as a Service of the National Library for the Environment.

9. Atsushi, I. and Y. Kiyoshi, 1999. Study on Characteristics of pollutant runoff into Lake Biwa, Japan. Water Sci. Technol., 39: 14-25.

10. Bykal, B., 1996. Alternative approach for evaluation of lake water quality: Lake Spancacase study from Turkey. Water Sci. Technol., 34: 73-81.

11. Anonymous, 2001. The report of Hydrological Studies. Water and Watershed Management Research Jahad Cooperation Publication.

12. Anonymous, 1998. U.S. Army Corps of Engineers. User's Manual for Water Quality for RiverReservoir Systems (WQRRS)., 1-2. 